\title{
INTERCÂMBIO VIRTUAL: \\ CONTRIBUIÇÕES PARA A APRENDIZAGEM DA LÍNGUA INGLESA DE ESTUDANTES DE LETRAS
}

VIRTUAL EXCHANGE:

CONTRIBUTIONS FOR PRE-SERVICE ENGLISH LANGUAGE TEACHERS

INTERCAMBIO VIRTUAL:

CONTRIBUCIONES AL APRENDIZAJE INGLÉS DE ESTUDIANTES DE LETRAS

\begin{abstract}
RESUMO
Reconhecendo o potencial da comunicação mediada por computador (CMC) e, mais especificamente, do intercâmbio virtual para a aprendizagem de línguas estrangeiras, este estudo de caso descritivo e de cunho etnográfico tem como objetivo investigar como a participação em um intercâmbio virtual (O'DOWD, 2018) pode contribuir para a aprendizagem da língua inglesa e o desenvolvimento da competência comunicativa de estudantes de Letras em uma universidade federal. A pesquisa tem como contexto o Projeto International Virtual Exchange (IVE), desenvolvido pelo Mororan Institute of Technology, no Japão, que utiliza a plataforma Moodle para as interações entre estudantes universitários de cursos de inglês como língua estrangeira em diferentes países na Ásia, Europa e América do Sul a partir do uso do inglês como língua franca (HAGLEY, 2017). O estudo buscou identificar o engajamento e participação dos estudantes brasileiros no intercâmbio virtual e a sua percepção em relação às contribuições do intercâmbio para a aprendizagem da língua inglesa e o desenvolvimento da competência comunicativa. A aquisição de vocabulário e o uso de tecnologias digitais foram identificadas como principais contribuições do projeto para a aprendizagem da língua inglesa.
\end{abstract}

PALAVRAS-CHAVE: Aprendizagem de línguas mediada por computador. Língua Inglesa. Comunicação mediada por computador. Aprendizagem de língua estrangeira.

\section{ABSTRACT}

Acknowledging the potential of computer mediated communication (CMC), and especially virtual exchange for foreign language learning, this descriptive ethnographic-based case study aimed at investigating how the

Submetido em: 19/08/2020 - Aceito em: 01/11/2020 - Publicado em: 24/12/2020

1 Graduada em Letras (Português-Inglês) pela Universidade Federal do Rio de Janeiro - UFRJ (1996) e Mestre em Tecnologia Educacional nas Ciências da Saúde pelo Núcleo de Tecnologia Educacional para a Saúde da UFRJ (2007). Doutora em Lingística Aplicada pelo Programa Interdisciplinar de Pós-Graduação em Linguística Aplicada na Universidade Federal do Rio de Janeiro (UFRJ). Professora Adjunta de Língua Inglesa no Departamento de Letras Estrangeiras Modernas do Instituto de Letras da Universidade Federal Fluminense (UFF) e pesquisadora do Núcleo de Pesquisas em Linguagem, Tecnologia e Educação (LingNet/UFRJ) e Núcleo de Estudos Críticos em Linguagem, Educação e Sociedade (NUCLES) com investigação nas áreas de formação de professores para uso de TDICs, Novos Letramentos, Educação a Distância, Ambientes Virtuais de Aprendizagem, Comunidades Virtuais e Sites de Redes Sociais. 
participation in a virtual exchange (O'DOWD, 2018) may contribute to English language learning and the development of communicative competence of pre-service language teachers in a federal university. The context of the study is the International Virtual Exchange (IVE) project, developed by the Mororan Institute of Technology, in Japan, that uses Moodle for university students' interactions using English a lingua franca in different countries in Asia, Europe and South America (HAGLEY, 2017). The study investigated Brazilian students' engagement and participation in the virtual exchange and their perception on its contributions for English language learning and development of communicative competence. Vocabulary learning and use of digital technologies were identified as the main contributions of the project for student learning.

KEYWORDS: Computer mediated language learning. English language. Computer-mediated communication. Foreign language learning.

\section{RESUMEN}

Reconociendo el potencial de la comunicación mediada por computadora (CMC) y, más específicamente, el intercambio virtual para el aprendizaje de lenguas extranjeras, este estudio de caso descriptivo y etnográfico tiene como objetivo investigar cómo la participación en un intercambio virtual (O'DOWD, 2018) puede contribuir al aprendizaje del idioma inglés y al desarrollo de la competencia comunicativa de los estudiantes de Letras de una universidad federal. La investigación tiene como contexto el Proyecto de Intercambio Virtual Internacional (IVE), desarrollado por el Instituto Tecnológico Mororan, en Japón, que utiliza la plataforma Moodle para las interacciones entre estudiantes universitarios de inglés como lengua extranjera en diferentes países de Asia, Europa y América del Sur a partir del uso del inglés como lengua franca (HAGLEY, 2017). El estudio buscó identificar el compromiso y participación de los estudiantes brasileños en el intercambio virtual y su percepción sobre las contribuciones del intercambio al aprendizaje del idioma inglés y al desarrollo de la competencia comunicativa. La adquisición de vocabulario y el uso de tecnologías digitales fueron identificadas como las principales contribuciones del proyecto al aprendizaje del idioma inglés.

PALABRAS CLAVE: Aprendizaje de idiomas mediante computadora. Idioma en Inglés. Comunicación por medio de ordenadores. Aprendizaje de lenguas extranjeras.

\section{INTRODUÇÃO}

O ensino de línguas sempre utilizou as tecnologias disponíveis para a mediação pedagógica (PAIVA, 2013; WARSCHAUER; MESKILL, 2000), sejam elas tecnologias analógicas como o livro e o retroprojetor, até as mais modernas tecnologias digitais, como o quadro interativo e tablets. Hoje, as Tecnologias Digitais da Informação e da Comunicação (TDICs) constituem importantes instrumentos de mediação no ensino e aprendizagem de línguas ao permitirem fácil acesso a recursos e contextos autênticos para a aprendizagem formal, informal e não formal de línguas estrangeira (LE), tais como vídeos, podcasts, jogos, textos de jornais, revistas, $b \log s$, entre outros, possibilitando diversas inovações neste campo (MOTTERAM, 2013).

Além disso, a Internet e a Web 2.0 permitem que os estudantes exerçam papel mais ativo na aprendizagem de línguas a partir da interação entre falantes de diferentes idiomas no 
ciberespaço, mesmo que dispersos geograficamente, facilitando o compartilhamento de informação e a negociação de significados rumo à construção colaborativa de conhecimento. Tal fato nos permite vislumbrar novas abordagens educacionais advindas de maior comunicação e colaboração entre alunos e professores em comunidades virtuais no ciberespaço, ultrapassando os limites da sala de aula tradicional, além de maior autonomia, centralidade e protagonismo do estudante nos processos de ensino e aprendizagem de LE.

Nesse sentido, a comunicação mediada por computador (CMC) tem contribuído para a expansão da sala de aula de línguas ao permitir a interação entre aprendizes de línguas em diferentes países, que passam a contar com um contexto autêntico de comunicação e prática da língua estrangeira, possibilitando não somente o desenvolvimento de habilidades linguísticas, mas também de habilidades interculturais (O’DOWD, 2018; HAGLEY, 2017).

Reconhecendo o potencial das TDIC para a promoção de processos de ensino-aprendizagem ricos e significativos, este artigo apresenta resultados iniciais de uma pesquisa em andamento que visa investigar o potencial da comunicação mediada por computador (CMC) para a aprendizagem de língua inglesa no contexto da educação superior e da formação de professores de língua inglesa a partir da participação em um intercâmbio virtual utilizando o inglês como língua de comunicação internacional, ou língua franca. Para isso, apresentamos uma breve revisão da literatura sobre a CMC e aprendizagem de línguas e o intercâmbio virtual como uma possibilidade de expansão das oportunidades de aprendizagem de língua estrangeira e desenvolvimento de competência intercultural. Também apresentamos um projeto de intercâmbio virtual que envolve estudantes universitários em diferentes países e que utilizam a língua inglesa como língua de comunicação internacional. Em seguida, detalhamos os procedimentos metodológicos e apresentamos os resultados iniciais obtidos com a investigação. Concluímos o artigo com as principais contribuições do intercâmbio virtual para a aprendizagem da língua inglesa apontadas pelos estudantes e futuros professores de língua inglesa. 


\section{FUNDAMENTAÇÃO TEÓRICA}

\section{Comunicação mediada por computador (CMC) e aprendizagem de línguas}

O estudo sobre o uso de tecnologias na aprendizagem de línguas já se constitui um campo consolidado na Linguística Aplicada, que, desde a década de 1980, investiga as contribuições de tecnologias digitais para o ensino e aprendizagem de línguas estrangeiras. Dessa forma, a Aprendizagem de Línguas Mediada por Computador, ou em inglês, Computer-Assisted Language Learning - CALL, é um campo fértil de pesquisa que vem se desenvolvendo ao longo dos anos conforme os avanços tecnológicos abrem novas possibilidades para a área.

A criação da Internet, na década de 90, permitiu um novo tipo de comunicação, a comunicação mediada por computador (CMC), que consiste na comunicação eletrônica possibilitada por ferramentas como o e-mail e salas de bate-papo (chat), e que privilegiavam a comunicação síncrona ou assíncrona por meio de textos escritos. Posteriormente, outras ferramentas, tais como Skype, possibilitaram a interação via áudio e vídeo entre pessoas dispersas geograficamente, necessitando apenas de um computador, ou mesmo dispositivo móvel, conectado à Internet para esta comunicação.

Assim, a CMC trouxe enormes benefícios para o sistema de comunicação em geral, facilitando a interação entre pessoas distantes geograficamente de forma rápida e a um custo relativamente baixo, além de permitir a comunicação entre duas pessoas, comumente chamada de "um-para-um", ou entre várias pessoas, também chamada de "um-para-muitos". No campo de ensino de línguas, especificamente, a CMC permitiu a ampliação dos contextos de aprendizagem de línguas estrangeiras ao possibilitar a comunicação entre estudantes de línguas e falantes nativos da língua alvo, por exemplo.

Neste contexto, Warschauer (1997) defende um novo tipo de aprendizagem, a aprendizagem colaborativa mediada por computador, na qual estudantes em diferentes países podem aprender a língua estrangeira de forma colaborativa por meio da CMC. Para o autor, esse tipo de comunicação é baseado na relação entre texto, fala e aprendizagem sob uma perspectiva sociocultural, na qual os estudantes teriam a oportunidade de aprender a língua estrangeira em 


\section{Revista Docência e Cibercultura}

um ambiente social e cultural mais amplo no qual podem "aprender a língua, sobre a língua e através da língua” (WARSCHAUER, 1997, p. 471).

Para o autor, cinco características distinguem a CMC de outras mídias de comunicação: (a) interação baseada em texto e mediada por computador; (b) comunicação de muitos para muitos; (c) independência de local e tempo; (d) trocas a longa distância; e (e) links hipermídia. Dessa forma, na CMC os estudantes podem se comunicar por meio de mensagens de texto postadas em fóruns em um ambiente virtual ou por e-mail, que permite a comunicação em grupo (de muitos para muitos) de forma assíncrona e que independe de local ou de tempo. Além disso, o ambiente virtual permite o compartilhamento de links hipermídia para arquivos de imagem, som e/ou vídeo, que podem facilitar e/ou ampliar a comunicação, ilustrando conceitos ou representando ideias, por exemplo.

$\mathrm{O}$ autor defende, assim, o potencial da CMC para a promoção da aprendizagem de línguas colaborativa a partir da Hipótese de Entrada (Input Hypothesis) de Krashen, uma vez que os estudantes recebem diferentes tipos de input nas mensagens de texto trocadas no ambiente virtual. $\mathrm{O}$ autor também se baseia na perspectiva sociocultural de Vygostky ao examinar a interação em contexto social mais amplo. Para o autor, a aprendizagem colaborativa que ocorre durante a CMC é essencial para ajudar os estudantes de línguas a avançarem na sua zona de desenvolvimento proximal ao se comunicarem com pares "mais experientes".

Walker e White (2013) também enfatizam o potencial da CMC para a aprendizagem de línguas. Para os autores, as tecnologias digitais não somente permitem a construção de novos ambientes nos quais o uso da linguagem acontece, mas também aproximam interlocutores que não teriam oportunidades de interagir de outra forma. Além disso, os contextos digitais geram novos propósitos comunicativos, como novos gêneros discursivos. Os autores argumentam que enquanto a interação digital oferece recursos ricos para os aprendizes de línguas, novas culturas linguísticas passam a se desenvolver tanto em termos de uso da língua quanto de comportamentos culturais. Os autores abordam ainda questões relativas aos avanços da World Wide Web para o contexto de aprendizagem de línguas, tais como sites de redes sociais e jogos on-line, por exemplo, que ampliaram as possibilidades de interação entre falantes de 
diferentes línguas e culturas e o papel da língua inglesa neste cenário, utilizada como língua franca e como língua predominante no ciberespaço.

\section{Intercâmbio virtual na aprendizagem de línguas estrangeiras}

O intercâmbio virtual é um tipo de comunicação mediada por computador (CMC) que é muitas vezes confundida com outros termos, tais como telecolaboração, intercâmbio intercultural on-line, ensino de língua estrangeira intercultural mediado pela Internet, ambientes de aprendizagem em rede global, e-tandem ou teletandem (O'DOWD, 2018). Contudo, segundo o autor, o intercâmbio virtual pode ser considerado como um termo guarda-chuva que serviria de base para todas as demais abordagens, que podem apresentar diferenças entre si, como por exemplo, no caso do e-tandem e teletandem, que envolvem aprendizes de diferentes idiomas que aprendem, cada um a língua do outro, em um processo de colaboração virtual. Nesse sentido, o intercâmbio virtual pode ser realizado de duas formas: (1) single mode, quando apenas uma língua é utilizada, geralmente como língua franca, e (2) dual mode, quando duas línguas são utilizadas para propósitos de aprendizagem.

De acordo com o Intent Project Group, o intercâmbio virtual é definido como

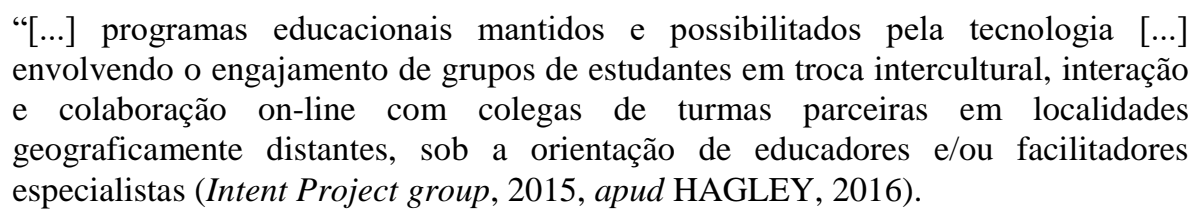

Para Hagley (2016), o intercâmbio virtual constitui um meio eficaz de possibilitar aos estudantes mobilidade virtual, permitindo que eles participem em uma comunidade global, utilizando a língua alvo em eventos comunicativos do mundo real, além de se tornarem mais conscientes culturalmente. Dessa forma, quando bem utilizado, o intercâmbio virtual pode constituir um método eficaz para melhorar as habilidades comunicativas dos estudantes e sua consciência intercultural.

Com base em diferentes estudos, Hagley e Thomsom (2017) apresentam diversos benefícios do intercâmbio virtual para o processo de aprendizagem de línguas, dentre eles destacam-se o 
aumento do nível de participação em eventos comunicativos, melhoria do feedback entre estudantes (peer feedback), e aumento de oportunidades de participar em, e aprender sobre outras culturas. Os autores defendem que o intercâmbio virtual pode constituir um recurso valioso na aula de língua estrangeira uma vez que os estudantes têm a oportunidade de interagir de forma regular e significativa com outros falantes da língua alvo.

Em pesquisa realizada no âmbito do projeto International Virtual Exchange (IVE), Hagley (2017) identificou que o intercâmbio cultural do tipo single mode, no qual apenas uma língua é utilizada como língua franca entre participantes de diferentes nacionalidades, constituiu não somente uma atividade útil para a prática da língua inglesa, mas também um importante motivador para a melhoria das habilidades linguísticas dos estudantes. Além disso, o pesquisador observou que, na perspectiva dos estudantes, o intercâmbio intercultural aconteceu de forma natural, uma vez que os estudantes desejaram trocar informações com estudantes de outras culturas.

Schenker (2013) também defende o uso do intercâmbio virtual nas aulas de língua estrangeira, uma vez que ele permite que os estudantes desenvolvam importantes habilidades no mundo globalizado, tais como a comunicação intercultural e a consciência cultural. Em pesquisa realizada com estudantes de língua alemã nos Estados Unidos e estudantes de língua inglesa na Alemanha, a pesquisadora observou que, a partir da experiência de intercâmbio virtual (dual mode), os estudantes tiveram a oportunidade de desenvolver a compreensão de diferentes culturas, melhorar as habilidades linguísticas por meio da comunicação aberta e autêntica, bem como por meio de discussões comparativas, além de se tornarem membros de comunidades transculturais e multilíngues dentro e fora de suas salas de aula.

Logo, o intercâmbio virtual apresenta-se como uma possibilidade de integração da tecnologia digital ao ensino de línguas estrangeiras, permitindo trocas culturais e o desenvolvimento de habilidades linguísticas ao oferecer aos estudantes um ambiente rico e autêntico para uso da língua alvo sob a perspectiva sociointeracionista.

Ao se considerar o contexto do curso de Letras em uma universidade pública, estas possibilidades se tornam ainda mais relevantes, uma vez que, muitas vezes, representam o 


\section{Revista Docência e Cibercultura}

primeiro contato dos estudantes (futuros professores de línguas) com falantes de outras línguas e culturas, permitindo ampliar seu repertório linguístico e intercultural e proporcionando situações autênticas de comunicação utilizando a língua estrangeira no processo de aprendizagem.

\section{O projeto International Virtual Exchange (IVE)}

O projeto International Virtual Exchange (IVE) foi criado em 2004 por Eric Hagley, professor e pesquisador do Mororan Institute of Technology, no Japão, e iniciado em 2005 em forma de projeto piloto com 10 estudantes universitários no Japão e 10 estudantes do Servicio Nacional de Aprendizaje, na Colômbia (HAGLEY; THOMSON, 2017). Desde então o projeto tem crescido e em 2018, já contava com cerca de 3000 estudantes e 180 professores em universidades no Japão, Filipinas, China, Tailândia, Emirados Árabes, Arábia Saudita, Espanha e Colômbia. ${ }^{2}$

O projeto é financiado pelo Ministério da Educação, Cultura, Esportes, Ciência e Tecnologia do Japão e não oferece custo para as universidades envolvidas, que participam de forma voluntária. O objetivo do projeto é oferecer aos estudantes universitários oportunidades de utilização da língua inglesa em contextos reais e autênticos que extrapolem os limites físicos da sala de aula de língua estrangeira.

A interação entre os estudantes é feita por meio de ambiente virtual na Plataforma Moodle, que constitui um Sistema de Gerenciamento da Aprendizagem (SGA) aberto e gratuito, utilizado em programas de educação a distância (EAD) e e-learning por diversas universidades em todo o mundo. Este ambiente é seguro e restrito aos participantes (coordenador, professores e alunos) do projeto, que apenas podem participar mediante o uso de login e senha pessoal (enviados pelo coordenador do projeto) e a supervisão de um professor responsável. Os estudantes são inscritos na plataforma pelo coordenador e organizados em pequenos grupos para facilitar a interação. Estes grupos são geralmente

\footnotetext{
2 Dados apresentados durante comunicação oral no 5th WorldCALL realizado em novembro de 2018 na Universidad de Concepción, no Chile.
} 
formados com estudantes de 3 países diferentes de forma a possibilitar o intercâmbio cultural e a negociação de significados por meio da língua franca.

A interação acontece em fóruns temáticos criados pelos professores e coordenador e buscam não só desenvolver a competência comunicativa dos estudantes na língua inglesa, utilizada como língua de comunicação internacional, como também trabalhar questões interculturais a partir da discussão de tópicos relativos à cultura de cada país envolvido no intercâmbio virtual. Os estudantes podem postar textos escritos ou em áudio, além de compartilhar arquivos de imagem e vídeos de forma assíncrona. Também é possível realizar comunicação síncrona por meio de videoconferência, apesar deste tipo de interação ser menos comum devido a questões de diferenças de fuso-horário e dificuldades de infraestrutura em alguns países. Toda a interação entre os estudantes é acompanhada pelos professores de cada turma, que desempenham o papel de guia e facilitadores da comunicação.

Os estudantes são, na sua maioria, estudantes universitários de diferentes cursos, que estudam inglês como língua estrangeira e possuem baixo nível de proficiência linguística (níveis A1 a B1 no Quadro Comum Europeu de Referência para Línguas - CEFR). As interações no ambiente virtual do projeto acontecem por cerca de 8 a 12 semanas a cada semestre, sendo que cada fórum temático fica aberto por cerca de 2 semanas para que os estudantes possam se comunicar e trocar informações relativas aos temas propostos.

Diferentes pesquisas em diversos países têm sido realizadas com base no projeto, tais como pesquisas sobre competência intercultural, empatia e compreensão cultural, cultura na aprendizagem de línguas, aquisição de vocabulário, entre outras (ROUX et al., 2018; HAGLEY, 2016; HAGLEY, HARASHIMA, 2017).

\section{METODOLOGIA}

Este artigo apresenta dados de uma pesquisa em andamento na Universidade Federal Fluminense e que visa a contribuir para a construção de conhecimento acerca da aprendizagem de língua inglesa por meio da comunicação mediada por computador e do intercâmbio virtual. A pesquisa enfoca o contexto universitário do curso de Licenciatura em 
Letras (Português-Inglês) e propõe a participação de estudantes dos primeiros períodos do curso (Língua Inglesa I a III) no projeto International Virtual Exchange (IVE). Assim, o objetivo geral da pesquisa é investigar como a participação desses estudantes pode contribuir para a aprendizagem da língua inglesa e o desenvolvimento da sua competência comunicativa.

Neste artigo, investigamos as contribuições da participação no projeto de intercâmbio virtual para a aprendizagem da língua inglesa, buscando responder as seguintes perguntas:

1) Como se deu a participação e engajamento dos estudantes no projeto de intercâmbio virtual?

2) Sob a perspectiva dos estudantes, quais as principais contribuições do intercâmbio virtual para a aprendizagem da língua inglesa?

A pesquisa se caracteriza como um estudo de caso descritivo (YIN, 2001; LEFFA, 2006) de cunho etnográfico (ANDRÉ, 1995; LEFFA, 2006), uma vez que busca uma investigação profunda do grupo de estudantes participantes, além da interpretação da sua visão em relação à experiência de aprendizagem a partir das interações realizadas no intercâmbio virtual.

Os participantes do estudo constituem 35 estudantes do curso de Licenciatura em Letras (Português-Inglês), sendo 15 estudantes inscritos na disciplina de Língua Inglesa 1 e 20 estudantes inscritos em Língua Inglesa 3 e que participaram no projeto International Virtual Exchange (IVE), realizado durante o primeiro semestre de 2019.

Os instrumentos utilizados para a geração de dados constituem: (a) relatório de participação gerado pela plataforma Moodle (utilizada no intercâmbio); (b) diário de aprendizagem dos estudantes realizado após a participação em cada fórum; (c) questionário final de avaliação da experiência; e (d) diário de campo da professora-pesquisadora.

O relatório de participação é gerado pela própria plataforma Moodle e permite identificar, sob uma perspectiva quantitativa, a participação dos alunos no ambiente virtual, ao indicar a quantidade de respostas de cada aluno às postagens nos fóruns, a quantidade de palavras 
utilizadas nas mensagens, bem como a quantidade de visualizações de mensagens durante um período de tempo informado.

Os diários de aprendizagem foram realizados durante as aulas em laboratório ao início/final de cada fórum/tema. O objetivo do diário foi levar os estudantes a refletirem sobre a experiência e o aprendizado a cada duas semanas bem como as dificuldades encontradas. Os diários foram escritos em Documento Google e postados na plataforma Google Sala de Aula, utilizada como parte da disciplina, sob a perspectiva da aprendizagem híbrida (blended learning). Para auxiliar a reflexão dos estudantes foram utilizadas as seguintes perguntas disparadoras: "Como foi minha participação no projeto ao longo dessas duas semanas?”; "O que eu achei da experiência"; Houve algum problema de comunicação com meus colegas estrangeiros? Caso afirmativo, como resolvi o problema?"; "Aprendi alguma coisa nova ao longo dessas duas semanas? O quê?”; "Que estratégias utilizei para compreender o que meus colegas escreveram no fórum?”; “O que eu espero nos próximos fóruns?"; “Como avalio esta experiência em relação ao meu aprendizado da língua inglesa?”. Na turma de Língua Inglesa I, pelo fato de os alunos serem iniciantes, o diário foi escrito em português. Já na turma de Língua Inglesa 3, os alunos ficaram à vontade para escolher entre o português e o inglês, sendo que a maior parte dos estudantes optou pela escrita em língua inglesa.

O questionário final de avaliação teve como objetivo identificar as percepções dos estudantes em relação às contribuições do intercâmbio virtual para a aprendizagem da língua inglesa. Por este motivo, foi respondido de forma anônima pelos estudantes para garantir maior veracidade das informações. O questionário foi criado no Google Formulários e postado no ambiente virtual de aprendizagem construído no Google Sala de Aula ao final da oitava semana do projeto.

O diário de campo da professora-pesquisadora consiste em notas de campo realizadas durante ou logo após as aulas com observações em relação à participação dos estudantes durante o trabalho realizado no laboratório.

Os dados foram gerados ao longo de oito semanas, no período de maio a junho de 2019, quando os estudantes participaram do intercâmbio virtual (2019 Spring International 
Exchange). A análise dos dados utiliza abordagens tanto quantitativas quanto qualitativas, de acordo com a natureza dos dados, caracterizando-se como uma pesquisa de abordagem mista. Os dados são apresentados no artigo da mesma forma como representados nos diferentes instrumentos de aprendizagem, incluindo erros de digitação, pontuação e acentuação, conforme a escrita dos estudantes. Estes são representados por números, de forma a proteger sua identidade.

Durante oito semanas, os estudantes brasileiros puderam interagir com estudantes em uma universidade no Japão e outra na Colômbia. As atividades foram realizadas tanto em sala de aula (laboratório), com orientação da professora-pesquisadora, quanto fora, acessando o ambiente virtual no Moodle. A interação no ambiente poderia acontecer de duas formas: (1) no fórum específico (Class to classes interaction), no qual os estudantes foram agrupados em pequenos grupos ( 3 a 5 estudantes de cada país) de forma a facilitar a interação em tópicos específicos, criados pelo coordenador do projeto; e (2) em um fórum aberto (Open Forum), no qual todos os estudantes poderiam interagir de forma livre em tópicos de interesse pessoal.

Os tópicos do fórum específico abrangeram os seguintes temas: (1) Apresentações; (2) Cultura alimentar; (3) Eventos em nossa vida; e (4) Tópico final: o que eu aprendi? Cada tópico tinha a duração de duas semanas para discussão. Além da participação nos fóruns, os estudantes também participaram de pesquisas (surveys) realizadas pelo coordenador do projeto no próprio ambiente do IVE. A figura abaixo ilustra a participação de uma estudante de Língua Inglesa I interagindo no fórum específico - Tópico 1: Apresentações. 
One of my hobbies is listening to music, so, when the music is in English, I usually read the lyrics and then I learn English and I love to do this. Besides, I love to read books with the most varied of genres, like science or biographies and watch movies while I eat popcorn =)

And you? What do you like to do?

140 palavras

Contagem das avaliações: -

Re: Group 2: Topic 1 - Introductions

por $\quad$ - Monday, 6 May 2019, 13:03

Hello, my name is and I'm a student of 3D animation, I'm from Colombia.

My hobbies are listening music,(I listening more music in English than in spanish), I like to exercise outside of home and I enjoy the landscapes of my city

I love the piano, and I would like to learn how to play piano professionally. I like movies and my favorite movies are "sing street" and "fight club"

I like to read adventure and suspense books

78 palavras

Contagem das avaliações: - Avaliar...

Link direto Mostrar principal Editar Interromper Responder

Figura 1. Interação no fórum principal (Class to classes interaction)

Fonte: https://iveproject.org/

O coordenador do projeto criava e iniciava a discussão em cada grupo de acordo com os temas dos fóruns e, a cada 15 dias, a professora-pesquisadora fazia a introdução dos temas e facilitava a interação no ambiente virtual. Os alunos deveriam, então, dar continuidade à participação nas discussões ao longo da semana. Desta forma, os estudantes poderiam manter contato com a língua alvo fora do ambiente da sala de aula, utilizando-a em situações reais de comunicação e ampliando as oportunidades de aprendizagem da língua inglesa.

A participação no projeto constituiu parte integrante da disciplina, sendo considerada como um dos instrumentos de avaliação da aprendizagem ao final do semestre. A professorapesquisadora apresentou os objetivos do projeto, bem como orientou na utilização da plataforma Moodle. Todas as aulas programadas para participação no projeto foram realizadas no laboratório do Instituto de Letras, onde os estudantes puderam utilizar computadores para acessar o ambiente virtual do projeto e interagir com os estudantes estrangeiros com a supervisão e auxílio da professora-pesquisadora. 


\section{RESULTADOS}

Nesta seção, apresentamos e discutimos os dados gerados pelos diferentes instrumentos de pesquisa de forma a responder as duas questões de pesquisa apresentadas anteriormente.

A primeira pergunta, "Como se deu a participação e engajamento dos estudantes no projeto de intercâmbio virtual?", busca investigar o nível de participação e engajamento dos estudantes no projeto. Para isto, utilizamos o relatório gerado pela própria plataforma do IVE (Moodle), que nos permitiu identificar a quantidade de respostas de cada aluno às postagens nos fóruns, a quantidade de palavras utilizadas nas mensagens, bem como a quantidade de visualizações de mensagens, como ilustrado nos quadros a seguir.

Quadro 1. Relatório de participação dos estudantes da turma Língua Inglesa I

\begin{tabular}{|l|c|c|c|}
\hline \multicolumn{1}{|c|}{ Estudante } & Respostas & Palavras & Visualizações \\
\hline Estudante 1 & 2 & 168 & 6 \\
\hline Estudante 2 & 12 & 449 & 47 \\
\hline Estudante 3 & 6 & 280 & 44 \\
\hline Estudante 4 & 9 & 691 & 27 \\
\hline Estudante 5 & 3 & 126 & 15 \\
\hline Estudante 6 & 14 & 775 & 40 \\
\hline Estudante 7 & 1 & 45 & 21 \\
\hline Estudante 8 & 15 & 1240 & 61 \\
\hline Estudante 9 & 9 & 474 & 46 \\
\hline Estudante 10 & 10 & 264 & 27 \\
\hline Estudante 11 & 25 & 1456 & 46 \\
\hline Estudante 12 & 2 & 127 & 8 \\
\hline Estudante 13 & 13 & 724 & 34 \\
\hline Estudante 14 & 4 & 558 & 20 \\
\hline Estudante 15 & 9 & 407 & 27 \\
\hline Total: & 134 & 7784 & 469 \\
\hline
\end{tabular}

Fonte: Plataforma Moodle utilizada no projeto

Na turma de Língua Inglesa I, os estudantes contribuíram com 134 respostas nos fóruns durante as oito semanas do intercâmbio, com uma média de 58 palavras por mensagem. 
Apesar de terem contribuído com apenas 134 mensagens, os alunos visualizaram um total de 469 mensagens, o que daria uma média de 31 mensagens por aluno. Nesse sentido, os estudantes teriam recebido input significativo gerando cerca de nove mensagens como output.

Já na disciplina de Língua Inglesa III, os estudantes contribuíram com 312 respostas e uma média de 50 palavras por mensagem, além de 1246 visualizações de mensagens postadas pelos estudantes estrangeiros, com uma média de leitura de 62 mensagens por aluno, conforme ilustrado no quadro a seguir.

Quadro 2. Relatório de participação dos estudantes da turma Língua Inglesa III

\begin{tabular}{|l|c|c|c|}
\hline \multicolumn{1}{|c|}{ Estudante } & Respostas & Palavras & Visualizações \\
\hline Estudante 16 & 2 & 140 & 18 \\
\hline Estudante 17 & 14 & 1280 & 131 \\
\hline Estudante 18 & 2 & 234 & 3 \\
\hline Estudante 19 & 4 & 385 & 35 \\
\hline Estudante 20 & 7 & 262 & 15 \\
\hline Estudante 21 & 7 & 292 & 31 \\
\hline Estudante 22 & 7 & 505 & 30 \\
\hline Estudante 23 & 19 & 1006 & 98 \\
\hline Estudante 24 & 39 & 947 & 199 \\
\hline Estudante 25 & 3 & 196 & 14 \\
\hline Estudante 26 & 12 & 1088 & 28 \\
\hline Estudante 27 & 5 & 252 & 18 \\
\hline Estudante 28 & 22 & 1275 & 55 \\
\hline Estudante 29 & 19 & 1528 & 46 \\
\hline Estudante 30 & 108 & 3725 & 361 \\
\hline Estudante 31 & 4 & 302 & 13 \\
\hline Estudante 32 & 17 & 714 & 45 \\
\hline Estudante 33 & 7 & 318 & 31 \\
\hline Estudante 34 & 10 & 811 & 246 \\
\hline Estudante 35 & 4 & 15707 & \\
\hline Total: & 312 & 447 & 12 \\
\hline
\end{tabular}

Fonte: Plataforma Moodle utilizada no projeto 
Considerando-se que o projeto foi realizado durante oito semanas, com quatro fóruns temáticos, e que a abertura de cada tópico foi realizada no laboratório da universidade com orientação da professora-pesquisadora, esperava-se que cada estudante participasse com, no mínimo, quatro mensagens (uma em cada fórum). Contudo, ao se considerar o objetivo de participação no projeto como possibilidade de ampliação das oportunidades de comunicação na língua estrangeira para além do espaço formal da sala de aula no curso de Licenciatura, esperava-se que os estudantes interagissem pelo menos uma vez por semana, totalizando, no mínimo, oito mensagens (respostas) ao longo do projeto. Esta expectativa, no entanto, foi alcançada com apenas nove estudantes da turma de Língua Inglesa I (60\% dos estudantes) e com nove estudantes da turma de Língua Inglesa III (45\% dos estudantes).

Conforme evidenciado pelos relatórios das duas turmas, o nível de participação e engajamento dos estudantes no intercâmbio virtual foi bastante assimétrico, havendo estudantes que contribuíram com apenas uma ou duas mensagens no fórum específico e outros que participaram ativamente, com até 108 mensagens tanto no fórum principal quanto nos fóruns abertos, como o estudante 15 da turma de Língua Inglesa III (ver Quadro 2).

Esses dados nos possibilitam identificar diferentes níveis de engajamento e participação no intercâmbio virtual, evidenciando estudantes que participaram apenas nas interações quando estavam presentes nos laboratórios, e outros que seguiram a proposta de manter a comunicação e a interação no ambiente virtual mesmo fora do espaço físico da sala de aula, expandindo as possibilidades de prática e aprendizagem da língua alvo para além do espaço formal de aprendizagem.

Possíveis justificativas para o baixo número de postagens nos fóruns podem ser evidenciadas nos excertos abaixo, retirados dos diários de aprendizagem dos alunos ao longo das seis primeiras semanas do projeto, nos quais alguns alunos relataram dificuldades em relação ao uso da plataforma Moodle e também falta de tempo para participar no intercâmbio.

A experiência do Intercâmbio Virtual é um boa oportunidade para aprender. Porém tenho dificuldade em utilizar esse tipo de recurso. Fiquei animada com esse tipo de exercício porém ainda não me sinto segura ou confiante para acessar o intercâmbio virtual. Espero superar essa dificuldade. (Estudante 5 - Língua Inglesa I-Semanas 1 \&2) 
Confesso que minha participação deixou um pouco a desejar. Acessei durante as aulas e umas duas vezes pelo app no celular. [...] (Estudante 13 - Língua Inglesa I-Semanas 1 \&2)

Ao longo dessas duas semanas, não tive muito tempo para conversar com os outros colegas de projeto, ao todo foram dois, mas pretendo aumentar a minha frequência de acesso nos próximos dias e assim o diálogo. [...] (Estudante 15 - Língua Inglesa I-Semanas 1 \&2)

[...] Novamente as semanas passaram rápido demais e eu não pude dar a devida atenção ao ive project como eu gostaria. [...] Apesar disso, tirei parte do dia de hoje para tentar recuperar o tempo perdido. [...] (Estudante 24 - Língua Inglesa III - Semanas 5 \& 6)

Infelizmente, ao longo do projeto, não tive tanto tempo para me dedicar de verdade ao IVE

Project. [...] Gostaria de realmente ter conseguido ter mais tempo para me dedicar é é realmente ter melhorado meu inglês com essa experiência. (Estudante 26 - Língua Inglesa III - Semanas 5 \& 6)

Apesar das dificuldades relatadas, os estudantes também compartilharam suas experiências e refletiram sobre sua aprendizagem e estratégias utilizadas para a compreensão e comunicação em LE, demonstrando seu engajamento e expectativas ao final da primeira semana do IVE e evidenciando a importância do projeto para o desenvolvimento do vocabulário, habilidades de leitura e escrita e a comunicação autêntica, além da aprendizagem sobre aspectos culturais, como evidenciado nos excertos a seguir:

A experiência com o Intercâmbio Virtual tem sido surpreendente, pois, no início, não imaginava que haveria muitos comentários. Então, me surpreendi ao poder ler meus colegas de grupo falando sobre o lugar em que vivem e se apresentando. Conhecer pessoas de outros países, ainda que virtualmente, é como ler um livro e conhecer novas histórias e pessoas que não imaginávamos. [...] Não achei difícil me comunicar, ainda que usasse a ferramenta de tradutor online para compreender uma palavra ou outra que não sabia o significado. Aprendi sempre algo novo porque acredito que a interação e a prática são essenciais no aprendizado de uma língua estrangeira, então tem sido um meio de manter o estudo do inglês. (Estudante 4 - Língua Inglesa I)

Considero a experiência no intercâmbio positiva. A interação com os estrangeiros colabora com o enriquecimento do vocabulário da língua inglesa, pois diante de alguma dúvida ou outra na escrita se recorre ao dicionário. [...] (Estudante 6 - Língua Inglesa I)

A experiência de conversar com outras pessoas de outras nacionalidades foi incrível, pois eu precisei de fato usar a língua inglesa para me comunicar. Além disso, acredito que isso seja importante para minha formação acadêmica como futura professora. [...] Eu espero que em breve eu possa desenvolver mais conversas, aprender mais sobre outras culturas, fazer amigos $e$ melhorar o nível do meu inglês. (Estudante 22 - Língua Inglesa III)

When I heard about the IVE Project, I was a little bit scared of using it because I'm too shy. After the first two weeks, I am still trying to talk more and not to be scared of making mistakes. I think I 
am making progress in English and being less shy because one thing that really help me was to realise that everybody in the IVE Project is not a native speaker and they are also trying to learn. The thing I most like about the project is to get to know new people from non-anglosaxon countries and the open forum (although I did not have free time to read all the questions). [...] (Estudante 34 - Língua Inglesa III)

Uma questão bastante interessante relacionada à aprendizagem de LE e levantada por uma aluna de Língua Inglesa I, foi em relação ao uso do intercâmbio virtual e de tecnologias digitais como estratégia de aprendizagem de LE. Nesse sentido, a CMC permitiu a comunicação com pessoas em locais distantes com as quais os estudantes possivelmente não teriam contato e permitiu o desenvolvimento de habilidades comunicativas, vistas como mais importantes do que a aprendizagem de regras gramaticais por métodos tradicionais.

\begin{abstract}
Achei muito interessante a proposta do IVE project. De fato utilizar as atuais tecnologias para a aprendizagem é algo muito interessante. Se libertar dos metodos tradicionais de livros com textos de conteudos quase sempre tao banais é algo que me interessa muito tambem para o aprendizado de uma nova lingua. Afinal, ja que temos que ler e ouvir uma nova lingua para aprende-la que sejam textos interessantes, construtivos, que instiguem o debate e o questionamento. Num primeiro momento usei o google translator para entender o que os outros estudantes diziam no forum. Mas logo nao precisei mais desta ferramenta e pude ir usando apenas o dicionario para me auxiliar. O que mais gostei é que uma lingua pode ter mil regras, mas o mais importante é se fazer comunicar. E neste fórum é esse o prazer que temos, o da comunicação. Mais interessante ainda é poder se comunicar com pessoas de lugares tao distantes, com as quais nao conversariamos normalmente. Na primeira semana consegui me familiarizar com uma primeira comunicaçao em ingles, que nunca tinha feito antes.[...] (Estudante 8 - Língua Inglesa I)
\end{abstract}

Após a sexta semana de interação no IVE, podemos perceber mais claramente as contribuições do intercâmbio virtual para a aprendizagem da língua inglesa e desenvolvimento de habilidades comunicativas. Os alunos refletiram sobre seu aprendizado ao longo das semanas, suas dificuldades e as estratégias utilizadas para facilitar a comunicação, conforme podemos identificar nos excertos a seguir:

Eu aprendi um pouco sobre a cultura colombiana e japonesa. Aprendi também que sou capaz de compreender em inglês mais do que eu pensava e que consigo escrever pequenos textos se eu tentar. Tive um pouco de dificuldade na compreensão porque meu vocabulário ainda não é muito vasto. Para compreender e principalmente para escrever precisei de ajuda do dicionário e também de ajuda de outra pessoa, principalmente para escrever. Sim aprendi algumas palavras que eu não conhecia e precisei procurar no dicionário. [...] (Estudante 3 -Língua Inglesa I)

O ive é uma atividade inovadora, porém em que não tenho facilidade de usar. Mas quando consigo participar, sinto feliz por estar compreendendo boa parte do que é abordado nos assuntos. Fica mais fácil quando estamos na sala e a professora está lá. Tenho tentado

\begin{tabular}{l|l|l|l|l|l|l} 
(C) Redoc & Rio de Janeiro & v. 4 & n.3 & p. 75 & Set/Dez 2020 & ISSN 2594-9004
\end{tabular}


compreender os assuntos no geral, sem me prender em uma ou outra palavra desconhecida, todavia quando a ideia central fica com a compreensão prejudica, acaba sendo necessário recorrer ao dicionário. [...] (Estudante 5 - Língua Inglesa I)

Estes dois excertos ilustram o quanto a experiência do intercâmbio virtual foi significativa no sentido de permitir maior consciência das habilidades de compreensão e comunicação na língua alvo bem como a aquisição de vocabulário e a estratégia de pesquisa em dicionários. Já o próximo excerto descreve algumas dificuldades encontradas, tais como a falta de tempo para a participação e as dificuldades e compreensão e produção escrita em língua inglesa, principalmente em relação à articulação de ideias. Além do uso do dicionário, o/a estudante relata o uso de ferramentas da internet para a pesquisa e aprendizagem sobre usos da língua.

Apesar de ter ficado mais ausente do que gostaria nestas semanas, eu adorei o tema do tópico 3. Foi meu preferido! Falar um pouco da minha cultura já foi interessante, porque pude refletir e aprender sobre ela. [...] Ainda tenho sido muito lenta para entender e escrever no fórum, o que torna a tarefa um pouco mais exaustiva do que deveria ser. Entretanto, tenho certeza de que é uma questão de prática e que quanto mais eu praticar, mais rápido vou conseguir me comunicar. Minha maior dificuldade não é o vocabulário em si, que consigo conferir num dicionário, mas sim em como estruturar as ideias. Tenho aprendido a cada dia novas formas de pesquisar na internet sobre as formas de se escrever em inglês. Usando os exemplos dos dicionários on-line, ou fazendo a busca na internet por uma expressão em específico para ver como ela é usada em contexto ou se tem textos explicando gramaticalmente como ela deve ser usada. [...] (Estudante 8 - Língua Inglesa I)

Além dos aspectos linguísticos, o/a estudante também aborda a importância do aspecto cultural do intercâmbio virtual ressaltando a importância da reflexão sobre a própria cultura. Este aspecto também é evidenciado por vários outros estudantes e ilustrado nos excertos abaixo, nos quais os estudantes ressaltam a importância da aprendizagem da língua e contato com outras culturas.

[...]A experiência de estar em contato com alunos falantes de inglês ao redor do mundo é fantástica e engrandecedora e eu queria que esse projeto fosse estendido. Além de aprender e aprimorar as habilidades com a língua inglesa, é possível criar laços com aquelas pessoas e eu acredito que isso seja de grande importância no meio acadêmico, principalmente em um curso de língua estrangeira. (Estudante 10 - Língua Inglesa III)

[...] Foi animador conhecer outras pessoas de nacionalidades diferentes com interesses iguais aos meus usando a língua inglesa como mediadora da comunicação. Acredito que essa minha interação proporcionou minha evolução na escrita da língua inglesa, além de enriquecer meu

\begin{tabular}{l|l|l|l|l|l|l|} 
(C) Redoc & Rio de Janeiro & v. 4 & n.3 & p. 76 & Set/Dez 2020 & ISSN 2594-9004
\end{tabular}


vocabulário e aprender mais sobre outras culturas como a japonesa. (Estudante 22 - Língua Inglesa III)

Estas e outras reflexões nos diários de aprendizagem evidenciam o quanto os estudantes perceberam a experiência como positiva, não apenas em relação ao desenvolvimento de habilidades linguísticas, como aquisição de vocabulário e desenvolvimento da escrita, mas também de habilidades de pesquisa na internet, uso de ferramentas digitais e de aprendizagem sobre diferentes povos e culturas. Contudo, a análise dos diários de aprendizagem permitiu identificar a aquisição de vocabulário como a principal contribuição do projeto, fato corroborado pelo questionário final de avaliação da experiência.

Este questionário foi respondido de forma anônima ao final da participação no projeto e contou com a participação de 16 respondentes no total (5 de Língua Inglesa I e 11 de Língua Inglesa III). As respostas evidenciaram que nenhum dos 16 estudantes havia participado de um intercâmbio virtual antes, sendo esta a primeira experiência. Destes, 43,8\% consideraram a experiência como muito boa, e 56,3\% como boa. Nenhum estudante relatou que a experiência foi indiferente, ruim ou muito ruim.

Em relação ao desenvolvimento das habilidades em língua inglesa após a participação no intercâmbio virtual, $25 \%$ dos estudantes avaliaram o desenvolvimento como muito bom, $62,5 \%$ como bom, e 12,5\% como indiferente. Na percepção dos estudantes, a maior contribuição do intercâmbio virtual para o desenvolvimento das habilidades linguísticas em língua inglesa foi em relação à expansão do vocabulário. Os seguintes excertos demonstram esta percepção.

"Eu aprendi novas palavras."

"Não senti melhoras, mas aumentei meu vocabulário."

"Conheci palavras novas por causa do intercâmbio virtual."

"Aprendi várias palavras em inglês da cultura japonesa, colombiana e brasileira."

"Expansão de vocabulário."

Os estudantes também relataram outras contribuições, tais como a habilidade conversacional e a interação em língua estrangeira, além da prática com a língua, conforme pode ser observado nos excertos a seguir: 
"Não discutimos a língua inglesa no projeto. Estávamos mais interessados nos assuntos das conversas do que na melhoria da língua. Mas nós conseguimos conversar sem dificuldades, então considero meu inglês bom."

"As aulas e as atividades foram mais proveitosas para mim, particularmente. Principalmente porque me dediquei mais a elas. Eu entro em contato com pessoas de outras nacionalidades pelas redes sociais, então não foi algo novo. [...]",

"Acredito ter melhorado as habilidades, também durante o curso de maneira geral, pois a prática é o melhor caminho para o aprendizado de um idioma."

"É sempre bom interagir com pessoas de outros países, no entanto, ainda tenho muita dificuldade com a linguagem oral."

"Gostaria de ter colocado "regular", pois não me acho em um nível "bom", mas também o desenvolvimento ao longo do projeto não foi "indiferente", aprendi coisas as quais me ajudaram no curso."

Enquanto professora e pesquisadora, por meio da análise dos registros no diário de campo, pude perceber o quanto a experiência auxiliou os estudantes no desenvolvimento de sua autonomia, uma vez que utilizaram diferentes ferramentas digitais para auxiliar na leitura e escrita de mensagens nos fóruns, tais como os aplicativos Grammarly e Google Tradutor, além de diferentes dicionários on-line, tais como Cambridge e Merriam-Webster (mencionados nos diários de aprendizagem). Estas ferramentas foram apresentadas aos alunos pela professora-pesquisadora no início da atividade de intercâmbio virtual e foi possível notar o uso recorrente das ferramentas ao longo das atividades realizadas no laboratório da universidade. Alguns estudantes também aproveitaram o momento de atividade em sala de aula para pedir feedback sobre sua escrita em língua inglesa, ampliando as oportunidades de aprendizado para além da aquisição de vocabulário.

Além disso, alguns estudantes realmente abraçaram a experiência e as levaram como estratégia para aprendizagem e desenvolvimento linguístico, relatando a participação intensa no fórum aberto (não obrigatório) e o início de amizades em outras plataformas digitais, tais como Instagran (fora do ambiente do IVE), expandindo as oportunidades de contato e prática da língua-alvo para além da experiência formal de aprendizagem na universidade. 


\section{CONSIDERAÇÕES FINAIS}

A partir dos dados aqui analisados, a experiência de participação no intercâmbio virtual foi avaliada como positiva pela maior parte dos estudantes. Como principal contribuição, eles destacam o desenvolvimento de habilidades linguísticas em língua inglesa, principalmente em relação à aquisição de vocabulário.

Nesse sentido, podemos concluir que a participação em um intercâmbio virtual com uso do inglês como língua de comunicação internacional (língua franca) pode contribuir para a aprendizagem da língua alvo e o desenvolvimento de habilidades linguísticas e comunicativas de estudantes em nível iniciante da língua inglesa no curso de Licenciatura em Letras (Português-Inglês), principalmente em relação à aquisição de vocabulário e o desenvolvimento de habilidades de pesquisa para a escrita. Outras contribuições do intercâmbio virtual incluem a expansão dos contextos de aprendizagem e uso autêntico da língua estrangeira em situações reais de comunicação que excedem os limites da sala de aula e conduzem à aprendizagem colaborativa e significativa.

Além disso, acredita-se que, ao participarem de uma comunidade multicultural, os estudantes aprendam a se comunicar de forma apropriada em diferentes culturas e desenvolvam consciência e competência intercultural. Estas habilidades são essenciais na sociedade contemporânea e no mundo globalizado, especialmente no contexto da formação inicial de professores de línguas.

Como limitações da pesquisa, destacamos que a mesma ainda se encontra em andamento e que deverá contar com a participação de novos estudantes em futuros fóruns do projeto. Esses dados possibilitarão aprofundar as contribuições do IVE para a aprendizagem da língua inglesa no contexto da formação de professores de línguas.

Por fim, essa pesquisa justifica-se pela necessidade vigente de apropriação e incorporação das novas tecnologias digitais aos processos de ensino-aprendizagem na cultura digital para promover práticas pedagógicas que extrapolem o espaço físico da sala de aula e que possibilitem a aprendizagem significativa em contextos autênticos de utilização da língua 
estrangeira. Apesar do avanço tecnológico e das diversas possibilidades que as tecnologias digitais oferecem para o ensino de línguas, nota-se que o campo ainda está muito preso ao ensino tradicional pautado em livros didáticos e alguns materiais multimídia (vídeos, hipertexto e arquivos de áudio), conforme apontado por uma das participantes deste estudo.

Portanto, a participação em um projeto internacional de intercâmbio virtual visa a contribuir para a transformação desta realidade, na qual os estudantes de Letras possam efetivamente utilizar a língua estrangeira para a comunicação em contextos autênticos, não se limitando apenas ao espaço físico da sala de aula na universidade. Além de oferecer aos estudantes a nova experiência de comunicação mediada por computador, o projeto visa, sobretudo, investigar as contribuições deste tipo de comunicação para a aprendizagem de línguas e identificar situações em que a aprendizagem ocorra por meio da interação on-line e não simplesmente por meio dos processos formais de ensino. Assim, a relevância do estudo reside na busca por diferentes recursos e metodologias que possam contribuir tanto para a melhoria das práticas de ensino-aprendizagem de línguas na universidade como para a formação de professores de línguas para atuação na cibercultura.

\section{REFERÊNCIAS}

ANDRÉ, Marli Elisa Dalmazo Afonso de. Etnografia da prática escolar. Campinas: Papirus, 1995.

HAGLEY, Eric Thomas. Making virtual exchange/telecollaboration mainstream - large scale exchanges. In: JAGER, S.; KUREK, M. \& O'ROURKE, B. (Eds.) New directions in tellecollaborative research and practice: selected papers from the second conference on telecollaboration in higher education. Research-publishing net, 2016. p. 225-230. Disponível em: https://www.researchgate.net/publication/310952590_Making_virtual_exchangetelecollaborat ion_mainstream_-_large_scale_exchanges> Acesso em: 19 ago. 2020.

HAGLEY Eric Thomas; HARASHIMA, Hideto. Raising the Intercultural Understanding and Skills of EFL Students through Virtual Exchange on Moodle. Proceedings of MoodleMoot Japan Annual Conference, volume 5, pp. 28-33, 2017. Disponível em: <http://hdl.handle.net/10258/00009540> Acesso em: 19 ago. 2020. 
HAGLEY, Eric; THOMSON, Haidee. Virtual Exchange: Providing International Communication Opportunities for Learners of English as a Foreign Language. Journal of Language and Culture of Hokkaido, n. 15, 2017. p. 1-10. Disponível em: < https://www.researchgate.net/publication/316599827_Virtual_Exchange_Providing_Internati onal_Communication_Opportunities_for_Learners_of_English_as_a_Foreign_Language>

Acesso em: 19 ago. 2020.

LEFFA, Vilson José. A aprendizagem de línguas mediada por computador. In: LEFFA, V. J. (Org.). Pesquisa em linguiística Aplicada: temas e métodos. Pelotas: Educat, 2006; p. 11 36. Disponível em: 〈http://www.leffa.pro.br/textos/trabalhos/B_Leffa_CALL_HP.pdf > Acesso em: 19 ago. 2020.

MOTTERAM, Gary. (Ed.) Innovations in learning technologies for English language teaching. London: British Council, 2013. Disponível em: $<$ https://www.teachingenglish.org.uk/sites/teacheng/files/C607\%20Information\%20and\%20C ommunication_WEB\%20ONLY_FINAL.pdf> Acesso em: 19 ago. 2020.

O'DOWD, R. From telecollaboration to virtual exchange: state-of-the-art and the role of UNICollaboration in moving forward. Journal of Virtual Exchange, 1, 2018. p. 1 - 23. Disponível em:

https://www.researchgate.net/publication/324729746_From_telecollaboration_to_virtual_exc hange_state-of-the-art and the role_of_UNICollaboration_in_moving forward> Acesso em: 19 ago. 2020.

PAIVA, Vera Menezes de Oliveira. O uso da tecnologia no ensino de línguas estrangeiras: breve retrospectiva histórica. In: JESUS, D. M. de; MACIEL, R. F. (Orgs.) Olhares sobre tecnologias digitais: linguagens, ensino, formação e prática docente. Coleção: Novas Perspectivas em Linguística Aplicada. Vol. 44. Campinas: Pontes Editores, 2015, p.21-34.

ROUX, Peter W.; KATSUAKI, Suzuki; RYUCHI, Matsuba; GODA, Yoshiko. Developing Cultural Intelligence (CQ): Designs for Blended Learning. International Journal for Educational Media and Technology, v. 12, n. 1, 2018, pp.18-28. Disponível em: < https://www.researchgate.net/publication/328092354_Developing_Cultural_Intelligence_CQ _Designs_for_Blended_Learning> Acesso em: 19 ago. 2020.

SCHENKER, Theresa. The Effects of a Virtual Exchange on Students' Interest in Learning About Culture. Foreign Language Annals, v. 46, n. 3, 2013. p. 491- 507. Disponível em: < https://onlinelibrary.wiley.com/doi/full/10.1111/flan.12041> Acesso em: 19 ago. 2020.

YIN, Robert K. Estudo de caso: planejamento e métodos. 2 ed. Porto Alegre: Bookman, 2001.

WALKER, Aisha; WHITE, Goodith. Technology Enhanced Language Learning:

Connecting theory and practice. Oxford: Oxford University Press, 2013. 
WARSCHAUER, Mark. Computer-Mediated Collaborative Learning: Theory and practice. The Modern Language Journal, n. 81, v. iv, 1997; p. 470-481. Disponível em: < http://education.uci.edu/uploads/7/2/7/6/72769947/cmcl.pdf> Acesso em: 19 ago. 2020.

WARSCHAUER, Mark.; MESKILL, Carla. Technology and second language learning. In: Rosenthal, J. (Ed.). Handbook of undergraduate second language education. New Jersey: Lawrence Erlbaum, 2000; p. 303-318. Disponível em: <http://education.uci.edu/person/warschauer_m/tslt.html > Acesso em: 19 ago. 2020.

Este é um artigo de acesso aberto distribuído sob os termos da Licença Creative Commons Atribuição Não Comercial-Compartilha Igual (CC BYNC- 4.0), que permite uso, distribuição e reprodução para fins não comerciais, com a citação dos autores e da fonte original e sob a mesma licença. 